\title{
O acesso a tecnologias pelas crianças: necessidade de monitoramento
}

\author{
Thaís Aluane Silva Santos ${ }^{1}$, Kátia Terezinha Alves Rezende², Ione Ferreira Santos² \\ e Silvia Franco da Rocha Tonhom ${ }^{3}$
}

\begin{abstract}
thais_aluane@hotmail.com; katia@famema.br; ionefs13@gmail.com; siltonhom@gmail.com
${ }^{1}$ Discente, FaculdadedeMedicina de Marília (Famema), R. Monte Carmelo, 800, 17519-030, Marília- SP, Brasil.

${ }^{2}$ Docente, Dra. em Enfermagem, Faculdade de Medicina de Marília (Famema), R. Monte Carmelo, 8oo, 17519-030, Marília- SP, Brasil.

32Docente, Dra. em Educação. Faculdade de Medicina de Marília (Famema), R. Monte Carmelo, 80o, 17519o3o, Marília- SP, Brasil.
\end{abstract}

DOI: $10.17013 /$ risti.38.48-63

\begin{abstract}
Resumo: Reconhece-se a importância dos avanços da tecnologia. Contudo, ela pode prejudicar o desenvolvimento da criança quando utilizada de forma inadequada. O objetivo geral dessa investigação é o de analisar o uso das tecnologias e seu impacto no desenvolvimento da criança. Os específicos, identificar quais são os meios utilizados pelas crianças e a intensidade do uso das tecnologias mais comuns; analisar como os responsáveis acompanham o uso e analisar os benefícios e os malefícios que as tecnologias trazem para a vida das crianças. O estudo foi realizado nas Unidades Básicas de Saúde de um município do interior paulista, onde entrevista-se o responsável que acompanhava a criança. Opta-se pela análise de conteúdo, modalidade temática. A análise dos dados nos permitiu identificar três temas: A) O acesso à tecnologia: conteúdo mais assistidos; B) O uso da tecnologia interferindo no desenvolvimento da criança e C) $\mathrm{O}$ monitoramento no uso das tecnologias.
\end{abstract}

Palavras-chave: Crianças; Tecnologias; Telefone Celular; Televisão; Desenvolvimento infantil.

\section{Children's access to technologies: need for monitoring}

Abstract: The importance of advances in technology is recognized. However,
it can impair the child's development when misused. The principal objective of
this research is to analyze the use of technologies and their impact on the child's
development. The specific ones, to identify which are the means used by children
and the intensity of use of the most common technologies, analyze how those
responsible control the use and examine the benefits and harms that technologies
bring to children's lives. The study was carried out in the Basic Health Units of São
Paulo City, where the person responsible for accompanying the child is interviewed. 
We opted for content analysis, thematic modality. Data analysis allowed us to identify three themes: A) The access to technology: most-watched content; B) The use of technology interfering with the child's development and C) Monitoring the use of technologies.

Keywords: Child; Technology; Television; Cell phone; Child development.

\section{Introdução}

Vive-se uma sociedade na qual presencia-se locais públicos, que possibilitariam o diálogo entre amigos efamiliares, entretanto, evidencia-se que as pessoas estão utilizando seus objetos tecnológicos, dificultando a troca de afetos. Nesse contexto, as crianças estão nascendo nessa cultura, e, atualmente, denominados "nativos digitais" (Pereira \& Arrais, 2015).

Nesse mundo globalizado, mais precocemente as crianças entram em contato com a tecnologia, construindo habilidades em seu manejo (Canaan, Ribeiro \& Paolla, 2017). Dessa forma, é essencial desenvolver capacidades instrumentais, sociais e éticas para o seu uso. Crianças e jovens devem ser impulsionados a selecionar, discernir e dar sentido a grande quantidade de informação a que são expostos, bem como, viabilizar o pensamento crítico para lidar com riscos e com as novas necessidades impostas pelo mundo do trabalho (Comitê Gestor da Internet no Brasil, 2018).

Com a chegada da Internet romperam-se as barreiras do tempo e do espaço, com informações em tempo real interligando as pessoas ao redor do mundo. Por meio dela, fronteiras foram quebradas encurtando qualquer distância e diferenças de cultura, espaço e condições socioeconômicas (Souza \& Oliveira, 2016).

Souza (2019) considera que as crianças podem se revelar nas ações e significados construídos nas suas brincadeiras, trazendo as vivências dos seus contextos socioculturais, combinando e criando outras realidades, tanto nas brincadeiras tradicionais quanto no uso de tecnologias moveis. A autora, procurando compreender como as tecnologias digitais móveis vêm contribuindo para o processo de produção das culturas infantis contemporâneas, identificou que as atividades relacionadas a cultura digital não implicam necessariamente na permuta das brincadeiras tradicionais pelas digitais e que e que as duas podem ser realizadas de forma equilibrada, sem, de maneira nenhuma, uma substituir a outra.

As crianças, ao interagirem com tecnologias móveis, ressignificam suas atividades lúdicas, criam experiências sociais e culturais de modo que surgem novos elementos que estruturam suas culturas infantis (Souza, 2019).

Becker (2017) destacou a importância das novas tecnologias na rotina infantil, explicitando uso lúdico de dispositivos tecnológicos, preferencialmente pelos móveis. Também se identificou que as tecnologias são concebidas como uma estratégia, a qual institui interações e trocas lúdicas por meio de formatos altamente inovadores de brincadeiras a longas distâncias.

Dessa maneira, a tecnologia tem sido crescentemente considerada pelas crianças como um importante meio por onde perpassam inúmeros relacionamentos, auxiliando os grupos de pares a garantir a permanência e a resistência das brincadeiras nas suas vidas, 
frente a rotinas altamente fragmentadas e funcionais, mas, sobretudo, assegurando o acesso aos amigos, companheiros de brincadeira e ao tão valorizado "brincar junto" (Becker, 2017).

No entanto, o aparecimento das tecnologias, que muito têm contribuído para o avançar da ciência, da medicina, da comunicação, têm paralelamente fomentado o isolamento dentro da sociedade e da própria família. É um estar junto no mesmo espaço, mas separado socialmente e afetivamente (Cruz, 2018).

Pereira e Arrais (2015) referem que as crianças aprendem muito cedo, a serem "dependentes" desses objetos. Sabemos que a sociedade contemporânea exige o domínio das ferramentas tecnológicas. É cobrado pela escola, pelo mercado de trabalho, em diversas situações sociais. Evidentemente há a preocupação e necessidade de inserir essas crianças nesse contexto o quanto antes possível. As crianças sentem-se atraídas por tais objetos, domina-os naturalmente e dedicam a estes considerável parte do seu tempo.

Até pouco tempo atrás, ser criança era brincar se relacionando com as outras por meio de divertimentos e para esses acontecerem, havia necessidade somente de ter disposição, imaginação, espaço físico. Brincadeiras que foram utilizadas pelos pais e avós, que foram sendo transmitidas de geração em geração. A vida não se resumia a ficar em casa na frente de uma tela, eram inúmeras formas simples de brincar, que divertiam. A insegurança nas ruas e a ausência dos pais em casa, pela necessidade de trabalharem, contribuem para que as crianças tenham uma infância limitada a tecnologia (Pereira \& Arrais, 2015).

Para Souza e Oliveira (2016) há também riscos a que as crianças são expostas como: ciberbullying, chantagens on-line, conteúdos agressivos e considerados impróprios para sua idade, vítimas de adultos mal-intencionados, pedofilia, etc., portanto, ainda indefesos à este tipo de criminalidade que se beneficia no ciberespaço, utilizando da vulnerabilidade dos adolescentes e crianças.

Finka et al (2019) identificou que o uso de tecnologia não interferiu sobre o desenvolvimento neuropsicomotor das crianças, relacionando que pode ser devido, ao mesmo tempo, haver a preferência por outros brinquedos e também ocorrer a mediação por adultos quando tiveram acesso as tecnologia.

Souza (2019) refere que as crianças se inserem na cultura digital porque seus pais possibilitam o uso dos dispositivos móveis, permitindo que as crianças se apropriem destes ressignificando a ideia de propriedade e considerando que o aparelho pertence a ambos. A autora ressalta a importância de os adultos serem mediadores da interação da criança com a tecnologia e o brincar, entretanto, identifica que isso ocorre quase sempre sem a intervenção ou mediação direta do adulto.

Pais e adultos responsáveis respondem pela idade a partir da qual seus filhos ou tutelados definem seus primeiros contatos com dispositivos comunicacionais. Em especial, no caso dos celulares, depende deles a autorização de uso, estabelecendo quando seus filhos são considerados aptos a manuseá-los, compartilhá-los ou a tê-los como seus. Para além dos desafios tradicionais de supervisão e acompanhamento do acesso à comunicação midiática, surgem outros associados à mobilidade e à privatização do uso (Sampaio \& Cavalcante, 2017). 
A Sociedade Brasileira de Pediatria aponta que é responsabilidade dos pais: conversar com seus filhos sobre a Internet e também sobre as redes sociais e quais os sites que são mais apropriados; alertar sobre os perigos e riscos da Internet ou encontros com pessoas desconhecidas em redes sociais ou fora delas; verificar a classificação indicativa para games, filmes e vídeos e conteúdos recomendados de acordo com a idade e compreensão de seus filhos; estabelecer regras e limites bem claros e "concordantes" entre todos sobre o tempo de duração em jogos por dia ou no final de semana; não fornecer cartões de crédito de uso pessoal; discutir mensagem ofensiva, discriminatória, ameaçadora, obscena, humilhante ou que contenha imagens ou palavras pornográficas ou violentas e como fazer para bloqueá-la; recomendar aos seus filhos que jamais forneçam a senha virtual a quem quer que seja, nem aceitem brindes, prêmios ou presentes oferecidos pela Internet, assim como também jamais devem ceder a qualquer tipo de chantagem, ameaça ou pressão de colegas ou de qualquer pessoa online; evitar postar fotos de seus filhos para pessoas desconhecidas ou público em geral (Azevedo, 2016).

Além dos pais e responsáveis, a escola também possui papel fundamental no desenvolvimento das crianças e adolescentes, para que estes lidem com as constantes mudanças decorrentes da transformação digital. O uso seguro e responsável da Internet deve passar por políticas públicas de educação equitativas e de qualidade e pela orientação e participação de pais e responsáveis na formação dos jovens (Comitê Gestor da Internet no Brasil, 2018).

Nas últimas décadas, as políticas públicas de promoção e proteção dos direitos de crianças e adolescentes têm sido tracejadas pelo esforço de articulação e fortalecimento de estratégias coordenadas e integradas de diversas políticas setoriais e intersetoriais nos campos da saúde, educação, assistência social, cultura, segurança e justiça, entre outras áreas (Egas, 2016).

Santos et al (2020) enfatizam a importância das ações políticas nesse contexto, tanto no setor da saúde como no da educação, buscando a integralidade do cuidado.

Gerasimczuk e Karageorgiadis (2016) analisando o movimento do comercio na área digital, tanto da oferta das redes quanto do consumo pelas crianças, assim como as ações de órgãos públicos na defesa da criança, entre outros aspectos, no Brasil, identifica o descumprimento da legislação vigente em defesa das crianças sugerindo que se faça mais estudos sobre esse contexto comercial, assim como uma maior reflexão da sociedade civil e dos órgãos públicos, anunciantes de mercado publicitário, sobre o uso comercial dos canais infantis pelas empresas afins.

Diante das pesquisas, é reconhecida a importância dos avanços da tecnologia atualmente, entretanto, compreende-se que esta pode tornar-se um sério problema prejudicando o desenvolvimento da criança. Dessa forma, acredita-se que no cotidiano dos serviços de saúde e no contexto de vida, as crianças utilizam de tecnologias de forma abusiva sem o acompanhamento dos pais e responsáveis.

Assim, questiona-se: Como as crianças utilizam as tecnologias? Quais são elas? Os responsáveis acompanham esse uso? De que forma? Qual o impacto (benefícios e malefícios) desse uso na vida da criança? 
Os objetivos desse trabalho é analisar o uso das tecnologias e seu impacto no desenvolvimento da criança; identificar quais as tecnologias mais comuns utilizadas pelas crianças; identificar a intensidade do uso das tecnologias mais comuns; analisar como os responsáveis acompanham o uso das tecnologias mais comuns e analisar os benefícios e os malefícios que as tecnologias mais comuns trazem para a vida das crianças.

\section{Metodologia}

Para alcançar os objetivos dessa investigação decidiu-se pela pesquisa de abordagem qualitativa. Para Minayo (2016) a pesquisa qualitativa trabalha com o universo dos significados, dos motivos, das aspirações, das crenças, dos valores e das atitudes, portanto, um sentido mais subjetivo e impressionista; produzindo uma compreensão e interpretação sobre o tema.

De acordo com a Resolução 466/2012 e a Resolução 510/2016do Conselho Nacional de Saúde que dispõe sobre as normas aplicadas a pesquisa envolvendo seres humanos, o projeto foi submetido ao Comitê de Ética em Pesquisa Envolvendo Seres Humanos da Faculdade de Medicina de Marília, sendo aprovado no dia 04-02-2019, parecer de número 3.130.691. As pessoas que concordaram em participar da pesquisa assinaram o Termo de Consentimento Livre e Esclarecido (TCLE).

O estudo foi realizado nas Unidades Básicas de Saúde (UBS) de um município do interior paulista. Nesse território municipal, no período estudado, estavam estruturadas 12 UBS distribuídas nas quatros regiões de saúde, norte, sul, leste e oeste. Foi escolhida aleatoriamente uma UBS por região, em que sua área de abrangência possuía um número maior de crianças na faixa etária de dois a deis anos.

A coleta de dados foi realizada com os responsáveis que acompanhavam as crianças no atendimento realizado nas referidas unidades de saúde, como consulta de pediatria e vacinação. O número de pessoas selecionadas seguiu o critério de saturação. Segundo Minayo (2014) o critério de saturação é atingido quando se consegue alcançar o entendimento das homogeneidades, da diversidade e da intensidade das informações buscadas. A saturação é observada através da repetição, redundância das ideias manifestas pelos pesquisados, não havendo, portanto, a necessidade da inclusão de novos participantes (Minayo, 2014).

Para a coleta de dados foi realizada a entrevista semiestruturada. Segundo Minayo (2016), esta se dá por perguntas abertas ou fechadas feitas pelo entrevistador sem se prender ao roteiro previamente estruturado. $\mathrm{O}$ roteiro deve ser elaborado em tópicos que buscam indicadores essenciais e suficientes para a pesquisa, servindo de orientação e guia para o diálogo entre o pesquisador e o entrevistado, assegurando a abrangência das informações desejadas (Minayo, 2014).

Dessa forma, o instrumento de coleta de dados foi elaborado com perguntas que buscavam dados para caracterização dos entrevistados: nome, idade, sexo, escolaridade, estado civil, ocupação, grau de parentesco, religião do entrevistado e idade, sexo e escolaridade da criança; e que procuravam responder as questões norteadoras: A criança faz uso de tecnologias? Quais são elas? Qual a frequência desse uso? A frequência altera nos finais 
de semana e nas férias? Como? Você ou alguém da família define período em que as tecnologias serão utilizadas? Se não, por quê? Se sim, como? Quais as reações da criança diante dessa definição? Você e ou alguém da família acompanha esse uso? Como? Você acha que o uso dessas tecnologias pode trazer benefícios para o desenvolvimento da criança? Quais são eles? Você acha que o uso dessas tecnologias pode trazer malefícios para o desenvolvimento da criança? Quais são eles? O uso da tecnologia compromete o estudo e o desempenho escolar? Você acha necessário/importante o acompanhamento do uso da tecnologia? Você deseja falar algo mais sobre esse tema?

Inicialmente foram contatados os responsáveis das crianças, na sala de espera, para vacinação ou consulta de pediatria sobre a pesquisa e o interesse em participar. As entrevistas foram realizadas por uma das pesquisadoras, atingindo uma saturação com 20 entrevistados, sendo que cinco responsáveis tinham duas crianças, totalizando 25 entrevistas.

As entrevistas tiveram uma duração média de 7 minutos e 85 segundos, foram gravadas com autorização dos entrevistados, transcritas fidedignamente, e para garantir o sigilo e o anônima todos pais e/ou responsáveis, eles estão identificados pela letra E, que se refere a entrevistado e numerados de 1 a 25 .

A análise dos dados foi realizada a partir do referencial teórico da análise de conteúdo na modalidade temática. Minayo (2014) considera que a noção de tema demonstra uma relação complexa entre uma palavra, frase ou resumo. Esta forma de análise tem como propósito identificar os núcleos de sentidos da comunicação e que representem algo para o alcance dos objetivos (Minayo, 2016). Nesse sentido, busca-se a compreensão dos significados no contexto da fala, nega-se e critica-se a análise de frequências das falas e palavras como critério de objetividade e cientificidade e ultrapassa-se o alcance meramente descritivo da mensagem, para atingir, mediante interferência, uma interpretação.

Inicialmente foi realizada a leitura exaustiva do material deixando-se impregnar pelo conteúdo, conseguindo-se ter uma visão do conjunto, apreender as particularidades, elaborar pressupostos, escolher a forma de classificação inicial e por fim definir os conceitos teóricos que orientaram a análise.

Em seguida, realizou-se a exploração do material distribuindo-se os trechos das entrevistas em uma classificação que contemplou analisar o uso das tecnologias e seu impacto no desenvolvimento da criança. A partir de então, realizou-se uma leitura do conteúdo de cada classe fazendo um diálogo entre as partes do texto de análise. Após identificou-se, por meio de inferência, os núcleos de sentido que reorganizados constituíram quatro temas apresentados no Quadro 1.

\begin{tabular}{ll}
\hline Núcleos de Sentido & Temas \\
\hline $\begin{array}{l}\text { - O meio tecnológico mais utilizado } \\
\text { - Conteúdo assistido de acordo com a idade. } \\
\text { - Conteúdo assistido inapropriado para a idade }\end{array}$ & $\begin{array}{l}\text { Tema1. O acesso à tecnologia: conteúdos mais } \\
\text { assistidos }\end{array}$ \\
\hline $\begin{array}{l}\text { - O uso da tecnologia contribui para o } \\
\text { desenvolvimento da criança. }\end{array}$ & $\begin{array}{l}\text { Tema 2. O uso da tecnologia interferindo no } \\
\text { desenvolvimento da criança }\end{array}$ \\
$\begin{array}{l}\text { - O uso da tecnologia não contribui para o } \\
\text { desenvolvimento da criança. }\end{array}$ & \\
\hline
\end{tabular}


- Os pais monitoram o uso de tecnologias

- Os responsáveis não monitoraram o uso das tecnologias.

Tema 3. O monitoramento no uso das tecnologias

Quadro 1 - Núcleos de sentido articulados aos temas

\section{Resultados}

\subsection{Tema 1- $O$ acesso à tecnologia: conteúdos mais assistidos}

Em relação ao acesso às tecnologias, captou-se que as crianças utilizam mais a televisão e o celular, em média, quatro horas por dia. Como a maioria das crianças estuda durante a semana, elas se conectam a essas tecnologias mais aos finais de semana e nas férias. Algumas não desfrutam dessas mídias nesse período, pois os pais e outros membros da família promovem atividades ao ar livre e ou dormem na casa de um amigo ou de parentes. Raramente os entrevistados citaram o uso de tablet e computador.

Os desenhos, os filmes e as novelas vistos na televisão denotaram ser de acordo com a faixa etária das crianças, pois são de classificação livre. "Ah, é Barbie, DPA e Ladybug, é o que ela gosta. Tem outros desenhos novos lá, é tipo a super poderosas também, é o que ela vê[...]; gosta da novela Poliana." (E24)

No entanto, há relatos de que as crianças assistem filmes com classificação a partir de 12 anos. E, também, programas de televisão para maiores de 10 anos. Portanto, as crianças estão acessando conteúdo inapropriado para a idade. "Ela gosta de assistir programas também de televisão, Eliana aos domingos. Se a gente sentar, ela gosta de assistir. Programa humorístico ela gosta bastante."(E19).

Quanto ao uso do celular identificou-se que as crianças se envolvem com vídeos educativos e interativos no YouTube, proporcionando o aprendizado em relação ao alfabeto, aos números e as cores, como também aprendem a cantar e, consequentemente, aprimoram o vocabulário. "Então, ela canta as musiquinhas, ela dança." (E8)

Algumas crianças, entre 7 a 10 anos, utilizam o YouTube para acompanhar canais de youtuber/blogueiros, o conteúdo desses está voltado para crianças dessa faixa etária. “[...] É blogueiro, Julia Mine Girl, Authentic Game e 2Marmortas.”(E17).

Também assistem vídeos sobre trollagem, no qual os entrevistados se preocupam, já que as crianças acabam reproduzindo o conteúdo assistido. "Ele gosta mais daquele vídeo de trollagem [...]" (E11).

O celular também é acessado para realizar pesquisa de escola, tirar foto, enviar áudio para parentes por meio do WhatsApp e jogos. "Roblox, Minecraft, e esses tipos de jogos. É, o Minecraft eu tinha uma ideia ruim, mas é criativo. Dá para construir, então eu acho até legal." (E22).

A minoria se conecta ao vídeo game e o faz, esporadicamente, com intuito de diversão. Algumas crianças assistem jogos com classificação livre e para maiores de 18 anos. "Ah, GTA! tem FortNite, tem futebol." (E11) 


\subsection{Tema 2- $O$ uso da tecnologia interferindo no desenvolvimento da criança}

Apreendeu-se que as crianças se entusiasmam quando podem assistir televisão ou acessar o celular, se tornam criativas e aprendem a contar número, a distinguir cores e a cantar as músicas. “Ah, um pouco animada sim, porque ela gosta bastando.”(E14)

Outro aspecto identificado pelos responsáveis, foi como possibilidade educativa, cujas crianças ao acompanharem os vídeos, indagam sobre atitudes desrespeitosas observadas e após orientação, elas compreendem os esclarecimentos. "Tem uns vídeos de umas meninas na internet que desobedece a mãe, aí briga, chora, aí ela começa a falar pra mim o que aconteceu, aí eu explico pra ela e falo: 'está vendo'; daí a mãe cansa da filha, vai embora e deixa a filha sozinha e a filha fica procurando a mãe... aí que explico pra ela, por isso que não pode desobedecer a mãe, porque acontece isso, a mamãe vai embora. O que acontece eu falo. E às vezes: 'está bom, eu vou obedecer'. Às vezes funciona."(E13).

O celular foi uma estratégia que encontraram para acalmar a criança e os pais/ responsáveis reconhecem que não é uma atitude apropriada. "O celular é uma maneira que a gente achou dela ver os vídeos dela, de dar um sossego, de dar uma acalmada nela e um pouco. [...], mas não é bom, a gente sabe o que não é bom.”(E13).

Outros entrevistados explicitaram que as crianças tornam se nervosas. Algumas permanecem em período integral jogando em casa. "Tem mania naquele jogo FireFree, que tem lá. Aí quando começa aquele jogo não pode nem chamar, porque senão é uma briga. Se deixar, ele fica o dia inteiro em casa."(E11).

As crianças reproduzem os comportamentos como a irritação e a desobediência observados nos vídeos e ou na televisão. "Às vezes eu não gosto que ela assista a PeppaPig, que ela fica muito irritada e ela fica desobediente” (E12).

Também mudam os comportamentos essenciais, como leituras e brincadeiras, para o desenvolvimento saudável da criança, comunicando-se de maneira agressiva após a aquisição do celular. "Porque ela depois que ganhou o bendito do celular mudou totalmente. Ela lia 2/3 livros por semana [...] Muda [comportamento]. Tanto, tipo, em gestos, verbalmente, porque tem muito palavrão, essas coisas, muda bastante”(E15).

A criança desenvolveu dependência ao uso do celular e o responsável realiza intervenções quanto a esse problema, no entanto, considera essa tarefa difícil. "Se deixar ela fica o dia inteiro. Ela viciou nesse celular. Essa madrugada ela acordou umas 5 horas [...] pedindo celular. Eu estou tentando tirar, mas está difícil”(E13).

A maioria afirma que as crianças se tornam mais espertas no sentido de construir novos conhecimentos. "Eu acho que é tecnologia é bom para aprender algumas coisas [...] no YouTube, que dá para você aprender coisas que você, vamos supor um curso de inglês, que eu não tenho como pagar, às vezes eu colocava vídeo para ela falar assistindo ir e aprender algumas coisas." (E17).

O uso da tecnologia na escola ensina as crianças a manusearem o computador e a realizaram pesquisa. "Eu acho, que lá na escola eles ensinam a digitar, apesar que hoje eles já sabem tudo, mas ensina sim. É bom. Ajuda na pesquisa [...] a saber mexer um 
pouco melhor no computador, dá uma base, uma noção de informática, aí eu acho legal isso.”(E21).

Outros preferem o método tradicional, onde as escolas não empregam tecnologias. "Não, tem que ser tradicional mesmo. Se não é demais, já basta em casa, ficar na escola também."(E6).

Aparece a ineficácia do desempenho escolar e o incentivo a atitudes não éticas. "Não, porque você mexe totalmente com a mente da criança. A criança fica entretida naquilo ali e [...] em vez de prestar atenção na aula, eles ficam pensando naquilo que eles estavam assistindo [...] mas, na verdade, eles estão tomando muita conta de crianças, que a criança hoje é muito entendida em jogos, vídeo games e isso está incentivando muitas coisas erradas." (E7)

\subsection{Tema 3 - O monitoramento no uso das tecnologias}

Em relação ao monitoramento quanto ao uso de tecnologias, identificou-se um constante acompanhamento do conteúdo acessado tanto pela televisão como pelo celular. Além do monitoramento, destacam também sobre o ensino de como realizarem buscas para esclarecimento de uma ortografia correta. "Tudo o que ele abaixa, nós sempre estamos por perto, nunca deixa sozinho, nada de ficar no quarto [...] e o que for baixar tem que me mostrar. Eu pego o histórico, vejo o que ele ta fazendo" [...] 'filho, não sabe uma palavrinha?' Eu ensino ele a estudar com o celular, o que? O dicionário. "vamos procurar como se escreve", porque às vezes nem eu mesmo sei a forma correta, então falo pra ele vamos ao dicionário (E4).

Reforçam preocupação com o conteúdo acessado, sinalizando que mudam o canal quando consideram inapropriado. "Assim, ele sabe que pode jogar futebol no vídeo game, nada de arma, nada de luta” (E4).

Depreendeu-se um cuidado com as crianças entre 7 a 10 anos, na qual, os responsáveis permitem o uso somente após se alimentarem e/ou realizarem os deveres estabelecidos. Evidenciou-se também a utilização de outras estratégias junto a criança para evitar a permanência do uso do celular ou mesmo da televisão. "A gente fala assim que tem suas obrigações [...] 'vai levar o lixo'." (E9); e "Eu levo ela para o curso [...] aí quando ela volta, eu já falo para ela tomar um banho dela [depois] já vai para TV.” (E17) e "Ah eu invento outra coisa 'vamos sentar no chão, vamos brincar de boneca, a mãe vai brincar com você ou então vamos lá fazer um bolo, ajudar a mamãe." (E10).

Embora os responsáveis pelas crianças argumentam sobre a importância do monitoramento do uso de tecnologia, relatam dificuldades de tempo para tal e por confiarem que as crianças não vão acessar programas impróprios. "Não, nem todos, porque tem muitos que ficam na história: 'não tem tempo', outros confiam nas crianças."(E20).

Consequentemente, as crianças permanecem um longo período do dia se conectando ao celular e ou assistindo televisão e aos bebês é permitido o acesso a vídeo no celular como forma de entreterimento.

Contudo, alguns entrevistados consideram desnecessário o monitoramento, não definindo limites, permitindo que a criança assista televisão em qualquer horário e os 
conteúdos que desejarem. Esses, em geral, são tias ou avós. "Não, não define [horário e conteúdo]. Ela fica mais a vontade" (E5).

\section{Discussão}

Diferentes pesquisas sobre consumos culturais de crianças e jovens demonstram que os jogos consomem tempo considerável da rotina de muitas crianças na contemporaneidade. No entanto, a especificidade do tempo de consumo dos jogos digitais varia conforme a cultura e as condições de viver a infância, sobretudo em relação ao acesso e pertencimento à cultura digital (Fantin, 2015).

Correa et al (2015) quando questionados sobre a relação dos seus filhos com as tecnologias, a maioria dos pais focou-se sobre a frequência com que aqueles as utilizam, poucos refletiram sobre essa relação. A falta dessa vai ao encontro da presença da televisão em grande parte da vida das crianças, já que os pais, por vezes, a utilizam como babá-eletrônica, corroborando para a formação de conceitos, atitudes e valores trazidos pela tela e que deveriam ser transmitidos pela família. Acresce-se a isso a utilização da tecnologia como forma de entretenimento (Santos et al, 2020).

Santos (2017) traz que a Academia Americana de Pediatria e a Sociedade Canadense de Pediatria recomendaram limites para a exposição das crianças a todo tipo de mídia (televisão, games, internet, smartphones etc.). Para as entidades, o ideal é que apenas depois dos dois anos de idade as crianças comecem a ter contato com esses aparelhos e por tempo limitado. Até os cinco anos, as crianças só deveriam ficar no máximo 1 hora diante das telas. O tempo aumenta para 2 horas para crianças de 6 a 12 anos e para 3 horas a partir dos 13 anos.

É necessário desencorajar, evitar e até proibir a exposição passiva em frente às telas digitais, com exposição aos conteúdos inapropriados de filmes e vídeos, para crianças com menos de dois anos, principalmente, durante as horas das refeições ou 1-2 h antes de dormir (Azevedo, 2016).

$\mathrm{E}$ as crianças menores de seis anos precisam ser mais protegidas da violência virtual, pois não conseguem separar a fantasia da realidade. Jogos online com cenas de tiroteios com mortes ou desastres que ganhem pontos de recompensa como tema principal, não são apropriados em qualquer idade, pois banalizam a violência como sendo aceita para a resolução de conflitos, sem expor a dor ou sofrimento causado às vítimas, contribuem para o aumento da cultura de ódio e intolerância e devem ser proibidos (Azevedo, 2016).

Canaan, Ribeiro e Paolla (2017) apontaram que as tecnologias digitais trouxeram para o universo das crianças uma nova cor, uma nova forma de brincar e aprender. Cabe na palma da mão o conhecimento sobre cores, frutas, animais e cantigas que os pequenos demonstram muito interesse. A partir disso, as crianças usam as tecnologias, tablet $e$ smartphones para jogar, assistir vídeos, ouvir músicas, ver e tirar fotos, o que estimula os sentidos, ajuda no desenvolvimento mental e no desenvolvimento da oralidade. Esses achados, também, foram demonstrados por essa pesquisa.

O interesse das crianças pelas redes, internet e mídias digitais parece não ser só de "interagir com a máquina” e sim com outras crianças. Dessa forma, o que está em jogo 
são os vínculos construídos e não a interatividade em si, pois crianças de diferentes contextos socioculturais, nas mais diversas condições estão aprendendo a brincar, a ganhar, a perder, a socializar e a se organizar em redes por meio da cultura digital (Fantin, 2015).

Se as fronteiras ou limites entre os jogos e games não são tão nítidos assim nos cenários da cultura infantil, sua presença na escola assume outros contornos. Muitos jogos considerados com potencial educativo e de ensino estão presentes na escola, inclusive em programas curriculares (Fantin, 2015).

Segundo Reinaldo et al (2016) as tecnologias de Informação e Comunicação (TICs) influenciam os métodos educacionais pela inserção de recursos digitais na área de educação que implicam em repensar o processo de ensino-aprendizagem para uma compatibilidade construtiva socio-interacionalista, na qual os estudantes criam, exploram, e integram conhecimento. Repensar esse processo a favor da aprendizagem é uma tarefa politico-pedagógica.

Para Cunha et al (2015) os professores possuem uma boa formação acadêmica e cursos de especialização, porém a maioria não possui capacitação para a inclusão das TICs em seu processo de trabalho. E, mais, esses docentes sentem necessidade e desejam uma formação para tanto e estão reivindicando políticas públicas, projetos e infraestrutura necessários.

A respeito dos jogos, a motivação está relacionada com o desejo de competir, mas também de colaborar. Há vários aspetos que as crianças, em particular os meninos, gostam nos jogos, como a sensação de conseguir ultrapassar um obstáculo, fazer a escolha acertada, explorar mundos de ficção ou ter algo para fazer quando se está sozinho; o mais valorizado é a competição (Monteiro \& Osório, 2015).

As meninas apreciam mais o Facebook, sobretudo da publicação de fotos e da troca de comentários sobre essas imagens. Esta partilha, individualmente ou em grupo, origina o que alguns participantes designaram de conversas, referindo-se à sucessiva troca de comentários. Os meninos também participam nestas interações, mas mais por meio da partilha de comentários do que da publicação de fotos (Monteiro \& Osório, 2015).

A pesquisa também corrobora com Monteiro e Osório (2015), os quais referem que a tecnologia além do seu forte componente de entretenimento, proporciona uma atividade intensamente social, por meio da qual a identidade, a reputação e o estatuto entre amigos/as se definem.

Entretanto, as crianças são sujeitos naturalmente espontâneos e criativos. Essa forte característica parece estar sendo corrompida pelas facilidades que as tecnologias propõem e à falta de mediação entre essas relações. Além do contato muito cedo e contínuo poderem influenciar no comportamento social (Pereira \& Arrais).

Cruz (2018) refere sobre os problemas relacionados ao desenvolvimento das crianças e adolescentes, identificando a crescente dificuldade de se manifestarem quando estão em grupo, em construírem uma identidade coesa, harmoniosa e integradora e que essa dificuldade advêm de matrizes familiares inconsistentes, de sociedades exigentes, que valorizam o individual em detrimento do coletivo, enfatizando resultados acadêmicos e o sucesso a qualquer custo. 
Em pesquisa de Finka et al (2019) não identificou influência negativa do uso de tecnologia para o desenvolvimento da criança devido relatos de que o consumo de algumas mídias ter sido mediadas e controladas em sua intensidade e tempo de uso.

Para Santos et al (2020) e Correa et al (2015) é perceptível como as tecnologias interferem em diversos aspectos da vida das crianças, que muitas vezes deixam de brincarem ao ar livre para permanecerem em seus domicílios, navegando na internet.

O excesso de elementos tecnológicos no cotidiano infantil afeta a convivência social e a saúde das crianças, pois elas não se nutrem corretamente, abusando de alimentos industrializados, quando estão frente à televisão ou ao computador; sendo agravado pelo dia-a-dia atarefado dos pais. Diante desse contexto, torna-se importante o papel da escola e dos professores na reeducação das crianças no que diz respeito aos cuidados com a saúde, oferecendo-lhes momentos de recreação e de atividades físicas (Correa et al, 2015).

Potencializa-se, assim, as premissas de Pereira e Arrais (2015), em que a educação deve começar em casa, mas a escola tem o dever de complementar, de buscar formas de caminhar ao mesmo passo que as tecnologias, pois os "nativos digitais" já chegam às instituições e ambas tem papel determinante na construção de sujeitos conscientes e informados.

Na presente investigação evidencia-se que alguns pais ressaltaram a importância das relações de seus filhos, isto é, de seu convívio com os amigos e a família. Os pais acreditam que a saúde das crianças está sob a responsabilidade deles e da escola, apontando que a falta de tempo e a correria do dia-a-dia são dificuldades enfrentadas na criação dos filhos, pois lhes impedem de desempenhar melhor as obrigações básicas de progenitores, reflexões essas que vão ao encontro de Correa et al (2015).

A Sociedade Brasileira de Pediatria aponta que é responsabilidade dos pais: conversar com seus filhos sobre a Internet e também sobre as redes sociais e quais os sites que são mais apropriados; alertar sobre os perigos e riscos da Internet ou encontros com pessoas desconhecidas em redes sociais ou fora delas; verificar a classificação indicativa para games, filmes e vídeos e conteúdos recomendados de acordo com a idade e compreensão de seus filhos; estabelecer regras e limites bem claros e "concordantes" entre todos sobre o tempo de duração em jogos por dia ou no final de semana; não fornecer cartões de crédito de uso pessoal; discutir mensagem ofensiva, discriminatória, ameaçadora, obscena, humilhante ou que contenha imagens ou palavras pornográficas ou violentas e como fazer para bloqueá-la; recomendar aos seus filhos que jamais forneçam a senha virtual a quem quer que seja, nem aceitem brindes, prêmios ou presentes oferecidos pela Internet, assim como também jamais devem ceder a qualquer tipo de chantagem, ameaça ou pressão de colegas ou de qualquer pessoa online; evitar postar fotos de seus filhos para pessoas desconhecidas ou público em geral (Azevedo, 2016).

Nesse sentido, salienta-se a importância do trabalho da equipe de saúde. Destaca-se a enfermagem, por sua formação generalista e atuação como educadora em saúde. Esse profissional pode ser o orientador dos pais na adequação dos seus hábitos de vida e dos de seus filhos, na busca pelo viver saudável, com relevância nas singularidades e pluralidades. Deve alertá-los sobre o mau uso das tecnologias pelas crianças e conduzir os pais ao acompanhamento e controle efetivo, uma vez que quando utilizadas didaticamente tornam-se potentes ferramentas para o desenvolvimento infantil (Correa et al, 2015). 
Canaan, Ribeiro e Paolla, (2017) referiram que alguns estudiosos que atuam no campo da educação afirmam a existência de limites que devem ser impostos para o bom uso das mídias digitais pelas crianças. Observa-se que os infantes vivem em dois mundos: o real e o digital/virtual, que por um lado se revela interessante, oferecendo aventuras e oportunidades, e por outro, perigo e riscos à saúde.

De acordo com a Política Nacional de Atenção Integral a saúde da Criança, é fundamental estimular a integralidade do desenvolvimento cerebral-mental-cognitivo-psicossocial dos primeiros anos de vida, com atividades familiares, nas escolas e na comunidade; também traz a importância de acompanhar esse desenvolvimento em todos os níveis de atenção à saúde (promoção, proteção, atendimento, detecção precoce e reabilitação de alterações) que podem repercutir na vida futura da criança. Considera que para a construção da autonomia da criança, a família e/ou responsáveis precisam de cuidados até que a criança adquira o senso de identidade (BRASIL, 2018).

Assim, corroborando com Santos et al (2020) "é importante que os profissionais da saúde e da educação estejam preparados para a identificação de problemas relacionados ao uso das tecnologias pelas crianças e que as ações para minimizar esses visem a integralidade do cuidado" (pp. 592-608).

Hoje, vive-se um momento difícil em que se enfrenta a pandemia do Sars - CoV2. Mudanças na forma de trabalhar, estudar, nos relacionar, brincar e conviver em casa foram necessárias devido às orientações de isolamento e distanciamento social, como uma das medidas importantes para a prevenção da transmissão desta doença. O uso das tecnologias torna-se maior e é considerado importante como solução para as limitações impostas por esse contexto. Assim, a Sociedade Brasileira de Pediatria reitera as orientações da organização Mundial da Saúde, nesse contexto, e orienta cuidados com o uso das tecnologias relacionados ao tempo. Considerando importante estar atento ao tempo para a saúde, tempo para o relacionamento afetivo, tempo funcional, tempo para a família, tempo para lazer, tempo para segurança (Eisenstein, 2020).

\section{Considerações Finais}

A pesquisa possibilitou analisar o uso de tecnologias e seu impacto no desenvolvimento das crianças, alcançando os objetivos a que se propôs.

Evidenciou-se o acesso à tecnologia e conteúdos mais assistidos; o uso da tecnologia interferindo no desenvolvimento da criança e o monitoramento no uso das tecnologias.

As tecnologias que as crianças mais acessam são a televisão e o celular, em média, quatro horas por dia. Raramente os entrevistados citaram o uso de tablet e computador, pois esses possuem a mesma finalidade do celular e vídeo game.

Em relação ao desenvolvimento da criança identifica-se que o acesso a tecnologias abre para novos horizontes, no entanto, há necessidade de instituir limites em relação ao conteúdo assistido de acordo com a idade e o tempo de utilização, pois seu uso indiscriminado pode trazer malefícios à saúde da criança. 
Constata-se que na sociedade atual não há como negar o acesso a tecnologias pelas crianças, porém elas precisam ser monitoradas pelos pais e ou responsáveis a fim de que as mídias acessadas possam contribuir para potencializar o desenvolvimento da criança.

Os professores e equipe de saúde, também, devem se responsabilizar pela educação em saúde junto aos familiares quanto a necessidade de monitoramento do uso de tecnologias.

Ainda que, a investigação se restringiu a uma população específica, permite aos profissionais, pais e educadores refletirem sobre o uso das tecnologias pelas crianças, limitando a sua utilização, bem como criarem novas alternativas de diversão, como por exemplo, o resgate de brincadeiras coletivas, vividas pelos adultos nessa fase.

\section{Referências}

Azevedo, A. E. I. et al. (2016). Manual de Orientação: departamento de adolescência. Saúde de crianças e adolescentes na era digital. 1(1), 1-11. https://www.sbp.com.br/ fileadmin/user_upload/2016/11/19166d-MOrient-Saude-Crian-e-Adolesc.pdf

Becker, B. (2017). Infância, tecnologia e ludicidade: a visão das crianças sobre as apropriações criativas das tecnologias digitais e o estabelecimentos de uma cultura lúdica contemporênea (Tese de Pós-graduação). Universidade Federal da Bahia- UFBA, Salvador, Bahia, Brasil. https://repositorio.ufba.br/ri/bitstream/ri/ 23851/1/BIANCA\%2OBECKER\%20-\%20TESE\%20VRS\%2OFINAL\%20\%28REPO SIT\%C3\%93RIO\%29.pdf

Brasil, Ministério da Saúde. (2018). Política Nacional de atenção integral à saúde da criança: orientações para implementação. Secretaria de Atenção à Saúde. Departamento de Ações Programáticas Estratégicas- Brasília-DF 1(1), 12-63. https://www.novaconcursos.com.br/arquivosdigitais/erratas/17392/24569/ politica-nacional-de-atencao-integral-a-saude-da-crianca-pnaisc.pdf

Canaan, M.; Ribeiro, L. \& Paolla, Y. (2017). Tecnologias digitais e influências no desenvolvimento das crianças. Universidade EaD e Software Livre, 1(8), 1-4. http://www.periodicos.letras.ufmg.br/index.php/ueadsl/article/view/12240/10437.

Comitê Gestor da Internet no Brasil (2018). TIC Kids Online Brasil: Pesquisa sobre o uso da internet por crianças e adolescentes no Brasil. Núcleo de Informação e Coordenação do Ponto BR. São Paulo. https://cetic.br/media/docs/ publicacoes/216370220191105/tic_kids_online_2018_livro_eletronico.pdf

Correa, A. M. G et al. (2015). Percepção de pais acerca do impacto de tecnologias no viver saudável dos filhos. Cogitare Enfermagem, 20(4), 805-812. https://revistas. ufpr.br/cogitare/article/view/41127/26787

Craveiro, P. S. U. (2016) Publicidade e infância: estratégias persuasivas direcionadas para crianças na internet. Revista do Programa de Pós-Graduação em Comunicação da Universidade Federal da Paraíba, 9(16), 17-29. https://periodicos.ufpb.br/ojs2/ index.php/cm/article/view/29357/15673 
Cruz, P. M. F. A. (2018). Impacto da tecnologia em grupanálise com crianças e adolescentes. Vinculo- Revista do NESME, 15(2), 83-90. http://pepsic.bvsalud. org/pdf/vinculo/v15n2/v15n2ao6.pdf

Cunha, A. L. et al. (2015). O professor de matemátia do ensino médio e as tecnologias de informação e comunicação nas escolas públicas estaduais de Goiás. RISTI - Revista Ibérica de Sistemas e Tecnologias de Informação, 4(9), 2-13. http://www.scielo. mec.pt/pdf/rist/nspe4/nspe4a02.pdf

Egas, H. (2016). Estratégias para a proteção integral de crianças e adolescents no mundo digital. In: TIC Kids Online Brasil [livro eletrônico]: pesquisa sobre o uso da internet por crianças e adolescents no Brasil 2016. Núcleo de Informação e Coordenação do Ponto BR. Comitê Gestor da Internet no Brasil: São Paulo. 141-148. https://cetic.br/media/docs/publicacoes/2/TIC_KIDS_ONLINE_2016_Livr oEletronico.pdf

Eisenstein, E. (2020). Recomendações sobre o uso saudável das telas digitais em tempos de pandemias da COVID-19. Sociedade Brasileira de Pediatria. 1-3. https://www.sbp.com.br/fileadmin/user_upload/22521b-NA_Recom_UsoSauda vel_TelasDigit_COVID19_

Fantin, M. (2015). Crianças e games na escola: entre paisagens e práticas. Revista Latinoamericana de Ciências Sociales, NiñezyJuventud, 13(1), 195-208. http://www.scielo.org.co/pdf/rlcs/v13n1/v13n1a12.pdf

Finka, K.; Mélob, T. R. \&Israeld, V. L. (2019) Tecnologias no desenvolvimento neuropsicomotor em escolares de quatro a seis anos. Cad. Bras. Ter. Ocup., São Carolos, 27(2), 270-278. https://www.scielo.br/pdf/cadbto/v27n2/2526-8910cadbto-2526-8910ctoAO1186.pdf.

Gerasimczuk, L. C. \& Karageorgiadis, E. (2016). Publicidade dirigida à criança na rede: ilegalidade nos canais de youtubers mirins. In: TIC Kids Online Brasil [livro eletrônico]: pesquisa sobre o uso da internet por crianças e adolescents no Brasil 2016. Núcleo de Informação e Coordenação do Ponto BR. Comitê Gestor da Internet no Brasil: São Paulo. 151-156. https://cetic.br/media/docs/publicacoes/2/ TIC_KIDS_ONLINE_2016_LivroEletronico.pdf

Minayo, M. C. S. Construção dos instrumentos e exploração de campo. (2014). In: Minayo, M. C. S. O Desafio do Conhecimento: Pesquisa Qualitativa em Saúde. (1th Ed.). São Paulo: Hucitec.

Minayo, M. C. S. O desafio da pesquisa social. (2016). In: MINAYO, M. C. S. (Org.). Pesquisa social: teoria, método e criatividade. (1th Ed.) Petrópolis: Vozes.

Minayo, M. C. S. Trabalho de campo: contexto de observação, interação e descoberta. (2016) In: MINAYO, M. C. S. (Org.). Pesquisa social: teoria, método e criatividade (1th Ed.). Petrópolis: Vozes.

Monteiro, A. F \& Osório, A. J. (2015). Novas tecnologias, riscos e oportunidades na perspectiva das crianças. Revista Portuguesa de Educação, 28(1), 35-37. http://www.scielo.mec.pt/pdf/rpe/v28n1/v28n1a03.pdf 
Pereira, B. S.; Arrais, T. S. (2015). A influência das tecnologias na infância: vantagens e desvantagens. Universidade do Estado do Rio de Janeiro, Rio de Janeiro. 4(1), 2-7. https://editorarealize.com.br/artigo/visualizar/10963

Reinaldo, F. et al. (2016). Impasse aos desafios do uso de smartphones em sala de aula: investigação por grupos focais. RISTI - Revista Ibérica de Sistemas e Tecnologias de Informação, 19(7), 78-89. http://dx.doi.org/10.17013/risti.19.77-92

Rivoltella, P. C. (2006). Screen Generation. In: Fantin, M. (2015). Crianças e games na escola: entre paisagens e práticas. Revista Latinoamericana de Ciências Sociales, NiñezyJuventud, 13(1),195-208. http://www.scielo.org.co/pdf/rlcs/v13n1/ v13n1a12.pdf

Sampaio, I. S. V.; Cavalcante, A. P. P. (2017). Mediação do acesso de crianças à comunicação mercardológica. In: TIC Kids Online Brasil [livro eletrônico]: pesquisa sobre o uso da internet por crianças e adolescents no Brasil 2016. Núcleo de Informação e Coordenação do Ponto BR. Comitê Gestor da Internet no Brasil: São Paulo. 173-178. https://cetic.br/media/docs/publicacoes/2/TIC_KIDS_ONLI NE_2016_LivroEletronico.pdf

Santos, J. (2017). Uso de tecnologia por crianças: benefício ou perda da infância? Paraná: Sempre Família. https://www.semprefamilia.com.br/tecnologia/ uso-detecnologia-por-criancas-beneficio-ou-perda-da-infancia/

Santos, T. A. S.; Rezende, K. T. A.; Santos, I. F. \& Tonhon, S. F. R. (2020). A influência da tecnologia no desenvolvimento da criança pré-escolar e escolar. In: Fornari, L. et al. (Eds.). Pesquisa Qualitativa em Saúde: avanços e desafios (volume 3) - NTQR ( $3^{\mathrm{a}}$, pp. 592-608). Oliveira de Azeméis - Aveiro - PORTUGAL: Ludomedia BuildingKnowledge. https://doi.org/10.36367/ntqr.3.2020.592-608

Souza, D. A. \& Oliveira, J. A. M. (2016). Uso de tecnologias digitais por crianças e adolescentes: potenciais ameaças em seus inter-relacionamentos. XIII SEGeTSimpósio de Excelência em Gestão e Tecnologia. 1(13), 3-4. https://www.aedb.br/ seget/arquivos/artigos16/952473.pdf

Souza, J. S. (2019). Brincar em tempos de tecnologias digitais movies (Tese de Pósgraduação). Universidade Federal da Bahia- UFBA, Salvador, Bahia, Brasil. https://repositorio.ufba.br/ri/bitstream/ri/28762/3/Joseilda.pdf 